\title{
AS CARTAS TROCADAS ENTRE JOÃO ANTÔNIO E ILKA BRUNHILDE
}

\section{THE LETTERS BETWEEN JOÃO ANTÔNIO AND ILKA BRUNHILDE}

\section{Cleia Garcia da Cruz Milan}

Doutoranda em Letras pela Universidade Estadual de Londrina

Mestre em Letras pela Universidade Estadual de Londrina

E-mail: gcmcleia@hotmail.com

\section{Regina Célia dos Santos Alves}

Doutora em Letras Teoria Literária pela Universidade Estadual Paulista Júlio de Mesquita Filho Professora do departamento de Letras Vernáculas da Universidade Estadual de Londrina

E-mail: gcmcleia@bol.com.br

\section{RESUMO}

O objetivo deste artigo é abordar a correspondência intensa que foi trocada entre João Antônio e Ilka Brunhilde, o que colaborou para a construção das personagens antonianas. O gênero carta, neste sentido, faz parte do universo dos escritores para troca de informações, para aconselhamento sobre narrativas que ambos escreviam, indo de crônicas aos contos premiados do autor João Antônio. As cartas estão no acervo do escritor em Assis-SP (CEDAP) e é uma importante fonte primária sobre a trajetória do mesmo, como jornalista, contista e também exposição da vida do autor que, para muitos pesquisadores, têm a ver com as personagens, com o gosto pela sinuca, pelo futebol, por músicas do Noel Rosa e outros. A contribuição de Ilka Brunhilde é, sem dúvidas, consolidadora da escrita do autor, mesmo porque, ela detinha arquivos originais, que o próprio autor havia perdido, por causa de incêndio em sua casa. A metodologia segue os preceitos de Bakhtin sobre o autor, criação verbal e estruturas dos enunciados. A pesquisa resulta em compreender as intenções discursivas do autor João Antônio, o uso de palavras da coletividade para explicar a própria sociedade. As trocas discursivas entre os autores possibilitou a João Antônio a força que precisava para continuar os seus objetivos, falar da marginalidade, conscientizando outras pessoas dos problemas brasileiros.

Palavras-chave: João Antônio. Ilka Brunhilde. Cartas. Dialogismo.

\section{ABSTRACT}

The purpose of this article is to address the intense correspondence that was exchanged between João Antônio and Ilka Brunhilde, which contributed to the construction of antonians characters. The gender letter, in this sense, is a part of the universe of writers to exchange information, for 
advice on narratives that both writing, ranging from chronic to the award-winning João Antônio's tales. The letters are in the writer's collection in Assis-SP (CEDAP), and are an important primary source about the history of the author, as a journalist, short story writer and displays the author's life, which incidentally, for many researchers identify with the characters, with the love for billiards, for football, for songs of Noel Rosa and so one. The contribution of Ilka Brunhilde is undoubtedly, the author writing consolidator, not least because she held the original files, which the author himself had lost because of fire in his home. The methodology follows the precepts of Bakhtin on the author, verbal creation and structures of utterances. The research results in understanding the discursive intentions of the author João Antônio, the use of collective words to explain the society itself. The discursive exchanges between the authors allowed João Antônio the power needed to continue his goals, speaking of marginality, advising other people of Brazilian problems.

Keywords: João Antônio. Ilka Brunhilde. Letters. Dialogism.

\section{INTRODUÇÃO SOBRE O AUTOR JOÃO ANTÔNIO:}

João Antônio escritor, jornalista, cronista, contista e um exímio escritor de cartas aos amigos. $\mathrm{O}$ autor manteve durante sua vida ativa correspondência com seus amigos e editores e uma organização com sua biblioteca particular o que permitiu que o seu acervo, pós-morte, fosse doado para a UNESP em Assis-SP. Não são todas as cartas que se tem licença para a leitura e investigação por pesquisa, visto que depende de outras pessoas que estão vivas a autorização para que o material seja divulgado. Porém, nota-se que é um arquivo precioso da memória e da fortuna crítica do autor.

Em suas cartas o autor costumava abordar as suas personagens e modo de existência delas, seu processo criativo, como também opinar sobre livros da literatura, crônicas de jornal e revista, mostrando-se também um intelectual deste universo. Entre essas cartas se destacam a intensa correspondência mantida entre ele e a escritora Ilka Brunhilde. Ela surge na história de vida do autor, como uma das pessoas fundamentais para o compartilhamento de suas ideias, como também, mostrou-se uma guardiã de manuscritos e emissora de opinião sobre as personagens dele.

\section{PERSONAGENS E CONTOS DE JOÃO ANTÔNIO E A OPINIÃO DA CRÍTICA SOBRE ELES:}

É como experiência do outro que João Antônio trata as suas personagens, como se elas fossem pessoas vivas no ambiente, dá-lhes vida, voz, oportunidade de existência: "repensar alguns 
personagens e viajar no tempo ou nos tempos de Paulinho Perna Torta, Zião da Gameleira, Ivinho Americano, Itiro Nakadaia, Laércio Arrudão, Ivete são personagens queridos com os quais, muitas vezes, me ponho a imaginar e resonhar" (ANTÔNIO, 2004, p. 04).

João Antônio menciona em entrevista no início da obra Patuléia (2004) sobre o conto “Afinação da arte de chutar tampinhas”, em que não há o marginal, mas o excluído pela pobreza, pela miséria, um universo que sempre se faz atual: "são quadros da miséria ou da pobreza vizinhando a penúria. Ainda há mendigos e engraxates pelas ruas e até em número maior" (ANTÔNIO, 2004, p. 4).

É que o estreante se revelava, desde logo, senhor dos segredos da arte de narrar, tinha a sua própria visão de mundo e trazia para o conto, ao lado de uma linguagem ricamente inventiva, desentranhada do coloquial da malandragem e habilmente engastada no fluxo da frase artística, todo um novo universo: o do pobre-diabo dos grandes centros urbanos, a gente sofrida dos subúrbios da vida, os pequenos burgueses quase proletários, às vezes quase pequeno-burgueses.

Segundo Mário da Silva Brito na orelha da obra Leão de chácara, João Antônio conseguiu seu lugar de destaque a partir de Malagueta, Perus e Bacanaço. Assim como outros da literatura, João Antônio migra do jornalismo para a literatura e ali faz sua arte e residência:

João Antônio mais uma vez vai buscar os seus personagens no meio do povo humílimo das grandes capitais (no caso de São Paulo e Rio de Janeiro), entre a arraia miúda que aprende a viver nos embates, trancos e barrancos da rua, postos à margem da ordem social, que suportam ou enfrentam de acordo com as circunstâncias (BRITO, 2002. Orelha do livro Leão-de-chácara).

Brito (orelha do livro Leão-de-chácara) escreve sobre essas personagens de João Antônio, demonstrando ao leitor essa impulsividade para a vida, protagonistas dotadas de uma realidade impressionante:

\footnotetext{
Nessas narrativas, sumarentas de vida e porejantes de verdade humana, não aparecem protagonistas marcados por traços pitorescos, que os transformem em coloridas figuras do folclore urbano. Pelo contrário: são o retrato veraz das camadas sociais a que pertencem, estão recortados com total fidelidade e na plenitude de suas grandezas e misérias (BRITO, 2002, Orelha do livro Leão-de-chácara).
}

O modo como as personagens narradoras se expressam é simples e direto, vai do seu sentimento de mundo em relação ao espaço urbano a que pertencem, utilizando-se de muitas gírias das pessoas simples na grande metrópole, para Mário da Silva Brito:

A vivacidade da linguagem de João Antônio, que sabe valer estilisticamente, dentro de sua fatura literária elaborada, o vocabulário, a sintaxe, a língua falada nascida do cotidiano popular. Ele é prodígio - e prodigioso - na valorização do idioma com que o povo se comunica (BRITO, 2002, orelha final do livro Leão-de-chácara). 
Brito complementa que essas mesmas personagens estão coladas do mundo real para o mundo ficcional, elas não compõem um cenário imagético, mas são definidas através da verossimilhança.

O que João Antônio faz é tratar a palavra de modo que compreenda os falares populares da região que viveu, o uso pode ser explicado por Bakhtin, como:

todo sistema de normas sociais encontra-se numa posição análoga; somente existe relacionado à consciência subjetiva dos indivíduos que participam da coletividade regida por essas normas. [...] Certamente, essa normas variam. Diferem pelo grau de coerção que exercem, pela extensão de sua escala social, pelo grau de significação social, que é função de sua relação mais ou menos próxima com a infraestrutura, etc. Mas, enquanto normas, a natureza de sua existência permanece a mesma; só existem relativamente à consciência subjetiva dos indivíduos de uma dada comunidade (BAKHTIN, 1991, p. 91).

No prefácio de Leão-de-chácara, Tania Macêdo trouxe uma frase de jornal de João Antônio ressaltando a importância da voz dele às atitudes cotidianas, o escritor que escreve a partir do vivido, da cidade, da sua experiência e que humildemente relata como o faz:

Fui percebendo que só se pode fazer arte se for com pele, vísceras, arrebatando o interior. Percebi também que eu tinha um tema - a malandragem [...] O homem precisa ter alguma grandeza, tem de ter um momento de Homem pelo menos. Meu único medo é passar pelas coisas e não vê-las (ANTÔNIO, 1976, s/p, Jornal do Brasil, 12 de jan. primary source).

Segundo Tania Macêdo a obra Leão-de-chácara se esgotou rapidamente logo na primeira edição em 1975, porque todos aguardavam, já que sua estreia fora surpreendente. Essa obra havia sido publicada doze anos após Malagueta, Perus e Bacanaço que já tinha obtido o título "Fábio Prado", também com premiação do "Jabuti", recebera outro de "Autor revelação", "Melhor livro de contos" (1963). O próprio João Antônio, em entrevista, teria reclamado por causa de tão longo tempo sem publicar, alegando o problema com as editoras do Rio de Janeiro, nominando ainda outros fatores, como sua mudança para o Rio de Janeiro, internação no sanatório, o seu trabalho em revistas e jornais. Neste período ainda escreveu outras obras, como:

Corpo a corpo (mais tarde lançado com o título de Malhação do Judas Carioca), Casa de loucos e Calvário e porres do pingente Afonso Henriques de Lima Barreto, além de publicar o conto "Paulinho Perna Torta" no volume Os Dez mandamentos, pela Editora Civilização Brasileira (MACÊDO, apud, ANTÔNIO, 2002, p. 6).

Tania Macêdo comenta que este espaço de tempo servira para que o autor aumentasse o seu próprio grau de perfeccionismo, visto que a obra apresenta um grau de amadurecimento na escrita. Em Leão de chácara, o autor muda o espaço de São Paulo para o Rio de Janeiro: "para ampliar horizontes e instalar-se no Rio de Janeiro, local que seria eleito, doravante, como cenário 
privilegiado da maioria de seus textos" (MACÊDO, Prefácio: "Malandros e merdunchos" In: João Antônio, 2002, p. 7). A estudiosa menciona o olhar atento que o leitor deve ter sobre a narração e as personagens, bem como, da ambientação que as sustenta, a paisagem descrita, quase sempre é a visão do real ou histórica dos lugares passados, as personagens contam as suas experiências neste universo:

Ao leitor desavisado vale lembrar, todavia, que a cartografia expressa nos textos transcende o mapa real, já que uma dose de sugestão se interpõe e, dessa forma, cada espaço é focalizado sob um olhar inquiridor que constrói a sua singularidade obtida, sobretudo, graças às ações e sensações dos personagens que percorrem ruas e becos, praças e ladeiras (Idem).

Sobre as narrativas de João Antônio, Tania Macêdo cita as personagens deste mundo habitado tanto em Leão-de-chácara quanto em Malagueta, Perus e Bacanaço, muito próximas das pessoas que vivem na cidade grande, ou seja, que estão à margem da sociedade:

\begin{abstract}
'marafonas, bandidetes, travestidos, jogadores, gente da noite, da polícia, picaretas', enfim 'gente descarrilada', que é enfocada a partir de seus próprios olhos e definida por suas próprias palavras. Ausenta-se, por tanto, o olhar 'de fora', o qual por certo redundaria em piedade ou desprezo por esses seres da margem (MACÊDO, apud, ANTÔNIO, 2002, p. 8).
\end{abstract}

Sobre como se tornara escritor, João Antônio responde como a mãe falara dele no tempo de criança:

[...] o caminho foi complicado. Minha mãe me contou que quando bem menino, uns cinco anos, eu ia para a porta de entrada da casinha térrea quando o sol se punha e voltava à noite. Pelo jeito como ela conta, eu ficava olhando aquele mistério todo, a majestade do nascimento da noite. Então, acho que aí me tornei um escritor (ANTÔNIO, 2004, p. 5).

O sentimento de ser escritor é tão profundo para o escritor como respirar ou viver, isso é ser escritor. O modo como olha para o mundo e o descreve. Hohlfeldt (1986, p. 06) considera que devemos estudar a narrativa de João Antônio em fases diferentes: a primeira consistiria por Malagueta, Perus e Bacanaço (1963) e Leão de chácara (1975). As personagens da primeira obra possuem estilos heroicos, são frutos da memória do autor, embora marginalizadas, na segunda obra se vê um caráter sociológico, como também uma "exorcização da marginalização", sentimento que paira na obra entre ficção e realidade.

A segunda fase corresponde à jornalística com as obras: Malhação de Judas carioca (1975) e Casa de loucos (1976) e com biografias: Calvários e porres do pingente Afonso Henriques de Lima Barreto (1977) e Noel Rosa (1982), Lambões da caçarola (1977); Copacabana (1978); Dedo duro (1982). Para Hohlfeldt há uma coincidência de opiniões da crítica sobe a obra de João Antônio: “a coincidência de opinião tem destacado que João Antônio ocupa-se 
dos marginais, dos malandros, dos otários, dos pingentes, dos suburbanos, enfim, dos esquecidos da sorte" (Idem). Hohlfeldt retoma o crítico Fausto Cunha que em 1970 já instaurava a importância de João Antônio no cenário da literatura brasileira, como autor revelação, ainda a se investigar o destaque deste para explicar a realidade do Brasil, que é também a mesma preocupação de Heloísa Buarque de Hollanda.

Outro teórico lembrado por Hohlfeldt (1986, p. 7-8) é Manoel T. Berlink, o qual menciona a necessidade de se refletir sobre o questionamento: "as populações marginais são marginais em relação a quê?” Segundo o estudioso essa marginalidade, em seu espaço e público populacional que se concentra fora do núcleo urbano central, isto é, restringe-se às favelas e à periferia, ou seja, um local em que se concentram as necessidades advindas do próprio sistema capitalista, como sua contiguidade. A cidade é aquela vista como "o grande crustáceo" que precisa se manter, com operários que são os trabalhadores das fábricas, porém as personagens de João Antônio, não são estas, mas sim, aquelas que estão no sistema urbano, mas fora do mercado de trabalho, são as pessoas que incomodam aquelas que são consideradas pessoas de bem e trabalhadoras.

Também Oscar Lewis é lembrado por Hohlfeldt (1986, p. 8) quanto à "cultura da pobreza", marcando os valores que identificam as diferenças das camadas sociais:

[...] nele se agrupam, indiferentemente, os lúmpen, o exército industrial de reserva e a superpopulação relativa, ou seja, o conjunto pauper, de miseráveis e paupérrimos, que no entanto são a base do sistema capitalista selvagem tal como se apresenta entre nós, e que, longe de se colocar sem importância na avaliação das populações economicamente ativas, constitui a base da chamada economia informal, em crescente expansão e essencial para a concentração capitalista. O chamado "pólo marginal", assim, tenha o nome que tiver, é um "fenômeno estrutural permanente" e, em sua ambivalência, tanto se apresenta integrado quanto diferenciado em relação às demais camadas populacionais hegemônicas.

Na visão de Hohlfeldt há uma ausência de trabalhos sobre o "lúmpen-proletariado" no Brasil, por isso a busca se concentra em Karl Marx em sua obra Manifesto do partido comunista. Um dos estudos que traz o tema é de autoria de Alba Zaluar em A máquina e a revolta, em que é citada a convivência no Rio de Janeiro de pessoas entre mendigos, malandros, migrantes e trabalhadores não fixos. A divisão de classes em João Antônio se dá por um lado pelos "otários" (trabalhador que procura se autossustentar honestamente) e de outro o "malandro" aquele que retira do primeiro todo o seu ganho:

O otário não é apenas o trabalhador igualmente marginalizado, uma vez que, a exemplo do que se vê no conto "Leão-de-chácara", por exemplo, também o executivo, uma vez na noite, transforma-se em potencial otário tanto da prostituta quanto dos demais malandros e bandidos que pululam pelo ambiente boêmio (HOHLFELDT, 1986, p. 9-10). 
Entre estes últimos existem regras de convivência, as quais devem se respeitar dentro do universo da "malandragem", que consiste em não entregar o outro à polícia, não revelar o esquema que costuma jogar, nem o nível de jogo do outro.

Quanto ao espaço Hohlfeldt (1986, p. 10) informa: “o que fica claro é que no conjunto de modificações, atingiu-se a ordenação da própria marginália ou do que como tal se convencionou chamar". Nos grandes centros e dependendo do lugar são presas fáceis: "assim, o otário da noite pode ser o malandro diurno. E o malandro noturno transforma-se no otário diurno" (HOHLFELDT, 1986, p. 12). Entre o lusco-fusco x alvorecer é o tempo escolhido pelas personagens para atuarem.

Quanto à estrutura o ponto-de-vista é do narrador observador, o que é ressaltado, mas, às vezes permite que seja pela voz de uma das personagens, terceirizando alguns momentos do conto por uma visão interna. De acordo com Hohlfeldt (1986, p. 13): “[...] de modo geral, valem-se da primeira pessoa do singular. Quando na terceira, o narrador, raramente onisciente, adere à personagem, faz sua perspectiva e o ponto-de-vista da personagem." É o que acontece, por exemplo, em "Malagueta, Perus e Bacanaço", em que somente Perus conhece a perspicácia do jogo de sinuca de Robertinho e não pode avisar os parceiros, por causa de regras do mundo das ruas.

Outra característica se dá pela circularidade, a narrativa in media res que retorna ao passado e mostra a confluência com o presente, demonstrando a realidade de que não há saída para a personagem. Também são utilizados flashbacks para estes retornos e exemplificações do que as personagens fizeram para chegar aquele estágio:

Quando na terceira, o narrador, raramente onisciente, adere à personagem, faz sua a perspectiva e o ponto-de-vista da personagem. Os contos jamais se organizam regularmente. Em geral sua estrutura é circularmente fechada: partem do presente, retornam ao passado, com o que criam o contraste, e ao voltarem ao presente evidenciam a situação crítica e de dependência ou derrocada em que se encontra a personagem. (HOHLFELDT, 1986, p. 13)

Outro recurso é o fluxo da consciência que faz o leitor desorganizar ou desconstruir a narrativa, para depois levar o leitor a entender o processo de devaneio pelo qual as personagens passam, vagando, falando sozinhos pelas ruas. Ou seja, ao final dos contos já possuem o resultado de suas escolhas, a falta de saída, demonstra a "sinuca" em que estão. Caminhos distintos os levariam consequentemente a outro destino, mas entram na vida "fácil", sabendo de seus truques, conhecedores do desfecho, é como jogar com a sorte, contudo, encaminham-se para isto mesmo sabendo das faltas de garantias e da insegurança instaurada: 
[...] o diminutivo é uma constante, como que numa espécie de ambíguo menosprezo e tentativa de aproximação que o malandro tenta junto ao otário, encobrindo o que na verdade sente: medo de tudo e de todos, e solidão carreada pelo medo e a necessidade de uma permanente vigília e autovalimento (Idem).

De acordo com Hohlfeldt as personagens de João Antônio tem que estar em constante fuga, vivenciar deslocamentos espaciais que lhes permitam sobreviver. A marginalidade das personagens está sempre ligada aos outros problemas que vão das más condições da infância, da subnutrição, das condições sociais, da mulher que na ausência do homem cria o filho ou mesmo a falta da família, também outras falências como da escola, da Igreja ou do estado. As personagens geralmente discursam para si mesmas, em uma tentativa de justificar a sua presença no mundo, a sua falta de sorte e também para encobrir a sua incapacidade para se manter no mundo tido como dos "otários".

Segundo Durigan (1983) em “João Antônio e a ciranda da malandragem” In: Os pobres na literatura brasileira, a crítica preparou várias expressões para se referir ao autor como: “o clássico velhaco", "escritor de submundo", "autor de marginalidade", "que trabalha com o livro da vida", "que escreve como um soco", contudo, não foi possível se fazer grandes interpretações da obra do autor, sendo o tema da pobreza de grande recorrência em seus contos: "nos contos, a representação da pobreza ganha contorno a partir da falta, da necessidade, em um contexto onde a riqueza e a 'felicidade' dependem do acúmulo" (DURIGAN, 1983, p. 214).

As personagens de João Antônio são “populares”, mas também possuem uma esperteza que não as levam em lugar algum, estão sempre sem dinheiro, sem condições de viver, mas não mudam sua posição social, pela facilidade que encontram nesse meio: “Outras certezas: em lagoa de piranha, jacaré nada de costas ou procura as margens. Quem vacilar e não for duro se estrepa. A vida não costuma fazer graça pra ninguém. É como a féria que eu cato no fim da noite; ela chega porque me viro (ANTÔNIO, 2002, p. 31).”

No conto "Maria de Jesus de Souza" é a mesma temática, a personagem sabe que não há saída, que tem que se submeter aos percalços, aos gigolôs ou aos policiais, mas não faz isso, prefere a rebeldia, apanhando, sofrendo e não vê saída para si mesma, porque prefere a prostituição a ter que trabalhar em casa de família ou em salão de beleza, a personagem não demonstra nenhum tipo de ascensão social, do mesmo modo como começa termina, em um tom do cotidiano que nos deparamos todos os dias que chega a nos assustar.

Segundo Ribeiro Neto a narração de João Antônio na maioria de suas obras dialoga entre as classes sociais e na sua briga constante, em que os guerreiros se digladiam, por dinheiro, por espaço social, como se as personagens fossem atores. Como se estivesse numa visão de fora o 
narrador na voz da personagem, da malandragem, vê o mundo do alto, como se tudo pudesse refletir, tentando explicar as diferenças e entender “os porquês”. É um mundo em que há “agressão" e "defesa", de um lado os malandros de outro os otários:

[...] os otários ou bacanas são as pessoas que fazem parte do sistema de produção: pessoas que têm uma vida estável, normal. São os fregueses das prostitutas, os adversários dos profissionais da sinuca, os que possuem dinheiro e o gastam. Os malandros ou merdunchos são os jogadores de sinuca, os cáftens, os ladrões, as prostitutas. São os que obtêm o dinheiro "na moleza". São os que tiram o dinheiro dos otários. Essa qualidade de otário, portanto, vem do fato de darem o dinheiro para os malandros. A qualidade de bacana vem da sua aparência de bem alimentados e bem vestidos, de pessoas da classe média. Os malandros, por sua vez, são merdunchos pela sua condição marginal, sem meio fixo de sobrevivência e sempre vivendo em situações de risco, como se a vida fosse um permanente "aqui e agora". O dinheiro não está no banco, mas no bolso do otário, que exige do malandro o exercício permanente da picardia para obtê-lo.

Malandros e otários estão, portanto, em luta permanente, mas essa luta só é dramática para o lado do malandro. Por isso, é sempre narrada da perspectiva do malandro, do merduncho. Isto é, o mundo nas histórias de João Antônio é visto do ponto de vista de quem está em posição social inferior. É o mundo visto pelo leão-de-chácara, pelo operário do subúrbio, pelo menino-engraxate, pelo jogador de sinuca, pelo morador do conjunto habitacional construído pelo governo, pela prostituta, pelo soldado. [...] É o ponto de vista de quem olha o mundo com ódio, "de bandido para bandido", como diz o próprio João Antônio. É assim que o merduncho olha para o otário, que o malandro olha para o bacana (RIBEIRO NETO, 1981, p. 103).

Embora essas personagens de João Antônio se aproximem por verossimilhança da realidade, elas são frutos da mente do autor e são ficcionais. As personagens são pensadas a partir da realidade que ele tem do universo paulistano e carioca, meios urbanos, em que a marginalidade se cria e a malandragem é ensinada, para sobreviver as personagens de seus contos se utilizam de qualquer método. $\mathrm{O}$ autor também parece se afeiçoar por demais a essas personagens do submundo. Na parte seguinte, o artigo pretende observar o viés destas personagens pelas opiniões trocadas por cartas entre João Antônio e Ilka Brunhilde.

\section{AS CARTAS ENTRE JOÃO ANTÔNIO E ILKA BRUNHILDE SOBRE SEUS CONTOS LITERÁRIOS:}

O autor em carta a Ilka Brunhilde comenta o seu apreço por São Paulo e por situações urbanas: "Também muito me interessam os problemas paulistanos e nos meus trabalhos vou registrando, ao meu jeito, coisas de São Paulo, cidade a quem amo, madrasta embora" (ANTÔNIO, 1 set., 1959). É deste espaço urbano que ele cria suas personagens fictícias baseadas em seu convívio na metrópole, com uma literatura que acabou por fazer a crítica considerá-lo autor marginal. 
É evidente na interação que acontece entre os dois, uma parceria dialógica que beneficia a ambos e os aprimora quanto ao estilo. Para Rodrigues, o gênero carta é:

tipificação social dos enunciados que apresentam certos traços (regularidades) comuns, que se constituíram historicamente nas atividades humanas, em uma situação de interação relativamente estável, e que é reconhecida pelos falantes. [...] A constituição dos gêneros encontra-se vinculada à atividade humana, ao surgimento e (relativa) estabilização de novas situações sociais de interação verbal. Em síntese, os gêneros correspondem a situações de interação verbal típicas (mais ou menos estabilizadas e normativas): cada gênero está vinculado a uma situação social de interação, dentro de uma esfera social; tem sua finalidade discursiva, sua própria concepção de autor e destinatário (RODRIGUES, 2005, p. 164-165).

As trocas dialógicas mantidas entre os escritores foram necessárias para as construções dos textos narrativos, principalmente, de João Antônio, formando um laço que permite através do outro a comunicação de sentidos:

a expressividade de um enunciado nunca pode ser compreendida e explicada até o fim se levar em conta somente o teor do objeto do sentido. A expressividade de um enunciado é sempre, em menor ou maior grau, uma resposta, em outras palavras: manifesta não só sua própria relação com o objeto do enunciado, mas também a relação do locutor com os enunciados do outro. [...] $\mathrm{O}$ enunciado do outro e a palavra do outro, conscientemente percebidos e distinguidos em sua alteridade, e introduzidos em nosso enunciado, incutem-lhe algo que se poderia qualificar de irracional do ponto de vista do sistema da língua, e em particular, do ponto de vista da sintaxe (BAKHTIN, 2000, p. 317-318).

Nestas cartas eles trocam informações acerca da literatura veiculada no país e também sobre seus posicionamentos sobre as narrativas. Em 23 de setembro de 1959, João Antônio escreve a Ilka falando da opinião de amigos dele sobre o "Meninão do caixote":

Acompanhe, se puder, a revista Anhembi, que é muito interessante. Lá muito possivelmente sairá um conto que atende pelo nome de "Meninão do caixote". Segundo a opinião de dois amigos, Mário da Silva Brito e Jorge Medovar a temática por mim ali erguida é completamente nova na literatura brasileira. Além do que, meus exagerados amigos, acham que o conto quase uma novela, é uma obra-prima [...] dou-me bem com todos os meus personagens. Gosto de amá-los. (ANTÔNIO, 23 nov., 1959).

O conto "Meninão do caixote", sem dúvida, é um dos melhores de João Antônio, porque apresenta uma personagem que é redonda, isto é, diferentemente de outras, o pensamento dela é mais forte do que o meio em que vive e das más influências dos amigos da sinuca e da malandragem, que ganham dinheiro fácil dos outros, através do jogo. Apesar de tudo o que a personagem adolescente passa o seu amor pela mãe é mais forte ou o amor da mãe pelo filho, fator importantíssimo nessas relações e que tira o menino da marginalidade.

No conto "Meninão do caixote" a personagem só desiste mesmo da vida de virar a noite jogando, sem se alimentar corretamente, indo de bar em bar em busca de parceiros de jogo, quando 
há a interferência da mãe, que não desiste do filho e vai até o fim para lhe buscar, levando-lhe uma marmita. É o carinho dela que o desmotiva para essa vida que, provavelmente, acabaria com a de seu mestre da sinuca Vitorino largado nas ruas, esquecido pelo sistema e por outros, dormindo de banco em banco, definhando até desaparecer, como é descrito no conto in media res. Na carta datada de 10 de novembro de 1959 João Antônio passa a Ilka Brunhilde o manuscrito de "Meninão do caixote", já com o aval de publicação por Mário da Silva Brito:

Este 'Meninão do caixote', muito embora já consagrado pelos que o conheceram, não me satisfaz totalmente, Ilka. Vai nisso sinceridade. É o tal de 'falta isso, sobra aquilo'. / Por isso o envio a v. Preciso opiniões. Contudo, hão de ser sinceras, porque de outras não preciso. Passo-lhe, pois, com o conto a liberdade de falar o que acha que ele é. Bom ou porcaria.

O que se pode observar nesses trechos é o início de uma grande amizade de João Antônio com Ilka Brunhilde e que vai comprometer o futuro dos dois, é nesta troca de cartas que se faz entender a literatura, as personagens, os ambientes, os posicionamentos ideológicos das personagens e até da alma humana. Para Bakhtin os: “[gêneros] são mais maleáveis, mais plásticos e mais livres do que as formas da língua. [...] A diversidade [dos] gêneros deve-se ao fato de eles variarem conforme as circunstâncias, a posição social e o relacionamento pessoal dos parceiros [...]" (BAKHTIN, 2000, p. 302).

Através das sombras, os escritores foram se afeiçoando um ao outro, em uma dependência que durou mais de vinte anos e que resultou em grandes projetos literários concluídos por parte dos dois.

Nestas correspondências trocadas João Antônio evidencia a sua intenção discursiva, falando das personagens com o objetivo de conscientizar sobre os problemas da coletividade. Para Bakhtin este intuito discursivo tem sucesso, quando as duas partes são conhecedoras dos enunciados:

o intuito, o elemento subjetivo do enunciado, entra em combinação com o objeto de sentido - objetivo - para formar uma unidade indissolúvel, que ele limita, vincula à situação concreta (única) da comunicação verbal, marcada pelas circunstâncias individuais, pelos parceiros individualizados e suas intervenções anteriores: seus enunciados. É por isso que os parceiros diretamente implicados numa comunicação, conhecedores da situação e dos enunciados anteriores, captam com facilidade e prontidão o intuito discursivo, o querer-dizer do locutor e, às primeiras palavras do discurso, percebem o todo de um enunciado em processo de desenvolvimento (BAKHTIN, 2000, p. 300-301).

Em 28 de setembro de 1959 João Antônio escreve à Ilka Brunhilde e dá detalhes do conto "Natal na Cafua", revelando o que o leitor percebe do texto, uma denúncia ainda que nas entrelinhas sobre o exército brasileiro: “"Natal na cafua' leva pouca invenção literária. Bastou que 
eu retornasse à memória da verde-oliva, repuxasse o tempo e rememorasse sargentos, cigarras baratas, misérias e condições próprias de um exército de um país como o nosso." O modo de escrever tanto no conto, como na carta demonstra a sutileza em se tratar do tema do exército brasileiro, visto que o destinatário e a remetente estavam em épocas da ditadura militar, porém se percebe pelo conteúdo da carta a vontade de extravasar: "Hoje estou muito contente. É preciso desabafar minha alegria com alguém que entenda. Afinal, não é somente defeito meu, esse. Até Beethoven dizia: 'o que tenho dentro de mim precisa sair"” (ANTÔNIO, 28 de set., 1959).

Um dado muito importante que consta nas respostas de Ilka Brunhilde a João Antônio diz respeito às suas personagens femininas que são poucas, ela entra na conversa falando do elogio que o autor faz a ela dizendo que é uma das poucas mulheres inteligentes que ele conhece, mas ela lhe afirma que igual a ela existe muitas e que ele deveria mencionar mais sobre as mulheres em suas narrativas. Por exemplo, sobre "Fujie" Ilka Brunhilde diz: "Como Fujie, meu amigo. Podemos falar dela agora, sem susto. Fujie é uma sobra. É o amor. Uma noção de mulher que desperta na consciência de um homem. A gente enxerga através das festas que ele faz, [...] do seu desvario, mas a gente sabe quem é Fujie, a mulher" (BRUNHILDE, 2 ou 4 de set., s/a).

A amiga Ilka Brunhilde o cobra sobre sua postura diante do feminino na literatura, mesmo em comparação ao real e finaliza com a afirmação: "João Antônio, dificilmente um homem conhece uma mulher. Digo também artisticamente [...] Você precisa começar a falar de suas mulheres. Perca o pudor diante delas. Desvende-se. Publique-as, uma a uma” (Idem).

Essa intensa correspondência entre os dois falava também de outros autores da literatura brasileira. João Antônio envia à Ilka Brunhilde, uma cópia do conto "Quarto de solteira" de Rubem Braga, em carta resposta, de dois ou quatro de setembro (1959/60?), ela diz o que pensa sobre o conto e o autor, atribuindo o assunto do mesmo a idade de Rubem Braga. Brunhilde termina a carta indicando para João Antônio "Natal solitário", romance de Maria José Pupo Nogueira e pedindo que o autor opinasse.

Em sete de março de 1960, João Antônio escreve à Ilka falando sobre o serviço dela em uma página literária dirigida por padres, revelando que gostou que ela tivesse deixado o emprego, para isso faz uso de uma frase de Mário de Andrade: "cada qual no seu cavalo", referindo-se que “soldado na caserna, padre na igreja. Eles não pensam que o seu domínio já é exagerado".

Em contato direto um com o outro, João Antônio escreve a Ilka falando do seu apreço por três perfis para personagens que ele gostou:

Amo. Malucamente adoro três vagabundos numa noite paulistana com suas misérias, camaradagens e um relógio de pulso. Trabalho na história de 'Malagueta, Perus e Bacanaço'. Tê-la-ia escrito não fôra um carnaval aluado em que me meti por acaso e no qual fiquei, por prazer. Não entendo a vida, Ilka, sem algum acontecimento novelesco. (ANTÔNIO, 7 de mar., 1960). 
A respeito do livro Malagueta, Perus e Bacanaço há várias histórias, uma delas dá conta de que teria acontecido um incêndio na casa de João Antônio queimando os originais, o que lhe teria obrigado a reescrever o livro todo de cabeça, segundo Azevedo Filho (2008, p. 15) que também investigou o acervo do escritor na UNESP de Assis, amigos conseguiram um lugar na Biblioteca Mário de Andrade para que ele pudesse novamente contar as façanhas de suas personagens, livro que ele dividiu em três etapas: Contos gerais, Caserna e Sinuca. As imagens construídas pelo autor dão conta do aspecto citadino vivenciado pelo "malandro", como fruto do sistema capitalista, ainda que esteja na ponta mais roída da corda, se considerar-se que "a corda sempre arrebenta do lado mais fraco" (provérbio popular):

A figura do malandro no conto "Malagueta, Perus e Bacanaço" é construída sem retoques. O universo social em que os malandros estão encravados é muito específico e João Antônio conseguiu como ninguém retratar tal cultura, tal modo de vida. Como grupo social, ou melhor, como extrato de um grupo social, o malandro é também um excluído no sistema capitalista. Só que seu "trabalho" é diferente, seu "batente" é outro, é específico (AZEVEDO FILHO, 2008, p. 16).

João Antônio dá vez e voz ao malandro, oferece a oportunidade de expressão, de representação do real, narrando o dia-a-dia das ruas. Ainda que outros escritores já tenham feito o mesmo procedimento, o escritor não o coloca como uma vítima do sistema, mas como um membro da sociedade, excluído por ela, mas participante desta, muitas das suas personagens são aquelas que não se encaixam na família, no conjunto de regras que as pessoas comuns passam, preferindo as ruas a ter que cumprir o protocolo familiar de café da manhã, almoço, jantar, repousar, fim de semana descansando, optam por vagar dia e noite, o tempo e o espaço se confundem na vida destes homens e mulheres, a rua se torna seu grande lar, aquela que os acolhe e os convida a ficar, como as personagens que gostam da sinuca, por exemplo, dão a vida e sangue para continuar as jogadas e as apostas, vagueiam dia e noite sem descanso, preferindo passar a noite vagando nas ruas, ao invés de pararem no hotel para descansar o corpo.

Ilka Brunhilde em quatorze de agosto de 1960 escreve a João Antônio sobre a busca que faz a pedido dele sobre textos que constavam para a publicação de Malagueta, Perus e Bacanaço, assim ela se expressa:

Releio todas as suas cartas, à procura de "Perus, Malagueta e Bacanaço". Não estão aqui em S. Paulo. Remexo baú de recortes, caixas, gavetas e nada. Amanhã volto a Campinas, lá continuarei a busca e se não encontrar o trecho que me confiou, nunca me perdoarei: principalmente, nesta emergência. Tenho todas as suas cartas, todos os contos impressos e datilografados: falta-me exatamente, exatamente aquele manuscrito e isso já parece coisa terrível do destino (BRUNHILDE, 14 ago., 1960). (sic.) 
Em outra carta datada em 16 de março de 1969, Brunhilde menciona o teatro "Cemitério de automóveis", dirigido pelo italiano Victor Garcia e protagonizado por Stênio Garcia, dizendo que lhe considerou terrível pela temática homossexual entre a simbologia, gritos, delírios e desvios. O ponto mais significativo destes diálogos por cartas, não é o conteúdo em si, mas a discussão entre os dois acerca da vida intelectual e a cultura brasileira.

Outra informação pertinente trocada entre os dois escritores consta a presença de indicação e consultas editoriais. Em 8 de agosto de 1968 Ilka Brunhilde escreve a João Antônio para passar o contato de um editor argentino e, ao mesmo tempo, pede-lhe informações a respeito da editora Civilização Brasileira, que é responsável pela maioria das publicações de João Antônio.

A contribuição de Ilka a João Antônio acontece por diálogos entre as cartas que estão carregadas de enunciados valorativos da obra do autor. Bakhtin (2000, p. 314) afirma que "nossos enunciados estão repletos de palavras dos outros, caracterizadas, em graus variáveis, pela alteridade ou pela assimilação, caracterizadas, também em graus variáveis [...]. As palavras dos outros introduzem sua própria expressividade, seu tom valorativo, que assimilamos, reestruturamos, modificamos".

Nota-se pelas cartas trocadas entre os autores um envolvimento afetivo entre eles e um rancor, demonstrando as crises que envolviam ora um, ora outro. Sobre Leão-de-chácara Ilka Brunhilde lhe escreve: "Não sei como você está, no Rio, na família, na literatura, na vida. E isso também nem me interessa. Eu só sei que nem li Leão-de-chácara, nem fui ao lançamento de seu livro - porque estava fazendo um espetáculo de poesia nessa noite e, se não estivesse, também não iria” (BRUNHILDE, 12 de out., 1975).

Já em 12 de dezembro de 1982 Brunhilde comenta sobre Dedo duro que considerou um "grande livro".

O trecho que traduz o tempo de correspondência entre os dois está na carta de 23 de abril de 1983, um dos mais comoventes e que dividem o escritor da pessoa que foi João Antônio:

Há 22 anos atrás (só isso?...) eu conheci um escritor jovem e inédito em quem acreditei. Acreditei tanto, que achei que era tarefa minha fazê-lo acreditar em si mesmo até o sucesso do primeiro livro. Depois, larguei-o (larguei-o?... e alguma vez você esteve preso a mim?...): achei que daí por diante ele não precisaria mais de mim. Ia conhecer gentes, mulheres de outro meio que não o que frequentava habitualmente, ia fazer carreira. Ia casar-se, certamente, como de fato aconteceu: aspiração latente nele, que eu percebia nas entrelinhas e subtextos de suas cartas e telefonemas. A mim, parecia-me estar ocupando um espaço (que espaço?...) provisório em sua vida. Sempre me pareceu detestável esse quadro de 'mulher mais velha, homem jovem e dependente'. E, afinal o quadro se desfez. O escritor fez carreira. Eu fiquei (BRUNHILDE, 23 abr., 1983).

Como de costume entre as correspondências dos dois, nesta mesma carta citada acima, comenta-se sobre um dos livros de João Antônio, trata-se de Malagueta, Perus e Bacanaço e a 
referência a ela como amiga que o auxiliou em Campinas na reconstrução das histórias, quando ocorreu o incêndio na casa dele que queimara os originais, ela possuía cópias impressas dos contos.

Nos longos discursos trocados, a discussão ocorre entre a literatura brasileira, poesias, romances, autores. Na carta de nove de abril de 1984 a autora expressa a alegria ao ver que João Antônio havia publicado uma poesia sua em um novo livro Bolhas, observando que era inédito vê-lo abordar um "relacionamento amoroso adulto", contando até mesmo que o autor inseria a personagem como um "homem objeto".

Entre as cartas a Ilka Brunhilde se destaca uma após a morte de João Antônio que é de Marília Andrade, ex-esposa de João Antônio, nesta ela relata o amor que o autor deveria ter por Brunhilde:

Sei que nos anos 60 éramos regidas por muito mais normas e códigos sociais do que hoje, mas, foi também uma época de quebra de tabus. E você era uma intelectual. Acho que o fato de que ele a colocava num pedestal, pouco abaixo (ou bem perto) do Olimpo foi o motivo pelo qual vocês não viveram totalmente esse amor. Me lembra Tomaz Antônio Gonzaga com Marília. Ele a amava, mas acabou nos braços de outra, ou outras [...] O pouco que conheço, foi lindo [...] Ele procurou por você ou alguém como você durante toda a sua vida (ANDRADE, 10 de fev., 1997).

O reconhecimento do amor entre Ilka Brunhilde e João Antônio pela ex-esposa do autor, confirmam a contribuição da autora na vida dele, bem como, na vida profissional, pela leitura que fez dos materiais, de originais, dos contos, dando palpites na construção das personagens. Se por trás de cada homem existe uma grande mulher, Ilka Brunhilde cumpriu sua missão quanto à literatura de João Antônio, uma pena que não tenham conseguido viver o amor que sentiram um pelo outro. João Antônio na visão de muitos críticos misturou sua vida pessoal à sua vida literária, fazendo-se como personagem de si próprio. Frequentou lugares de sinuca, samba e do baixo meretrício, teve várias mulheres, mas segundo sua ex-esposa Marília Andrade só amou mesmo Ilka Brunhilde, o resultado desta longa e fraterna amizade estão de algum modo nos registros do autor em seus livros, uma participação da amiga que só poderia tê-lo amado mesmo, visto que deixara por escrito a autorização para a publicação de suas cartas.

\section{CONCLUSÃO}

O que observamos com toda essa correspondência entre Ilka Brunhilde e João Antônio é de que um dependia do outro para escrever, a real importância de um escritor na vida do outro foi fundamental para o que hoje temos deles. 
Mesmo os documentos guardados por Brunhilde e que foi muito importante para a publicação de Malagueta, Perus e Bacanaço por causa do incêndio ocorrido na casa dele. Outra questão de suma importância é a organização dos dois quanto às cartas trocadas, percebe-se que eles davam valor a escrita e ao gênero carta, não se desfizeram das mesmas quando não estavam em sintonia.

Foi graças a esse compromisso entre eles e à literatura que hoje podemos consultar suas cartas no acervo de João Antônio. A condição para que possamos visitar o acervo e consultá-lo só é possível devido à autorização deixada por Ilka Brunhilde em vida, como também, assinamos termo de compromisso de que só usaríamos essas cartas para fins de pesquisa acadêmica sobre o autor. Nestas linhas estão o registro de como se deu essa amizade tão longa, mistura de afeição e dependência espiritual em que um autor era o apoio do outro.

\section{NOTA}

Lúmpen-proletariado: "escória integrada pelos elementos desclassificados de todas as camadas sociais e concentrada nas grandes cidades [. . . ] esse produto massivo da putrefação das camadas mais baixas da velha sociedade [. . . ] centro de recrutamento de gatunos e delinquentes de toda espécie, que vivem dos despojos da sociedade, pessoas sem profissão fixa, vagabundos [ . . ] lado a lado com roués decadentes, de fortuna duvidosa e de origem duvidosa, arruinados e aventureiros rebentos da burguesia, vagabundos, soldados desligados do exército, presidiários libertos, forçados foragidos das galés, chantagistas, saltimbancos, lazzaroni, punguistas, trapaceiros, jogadores, maquereaus, donos de bordéis, carregadores, literati, tocadores de realejo, trapeiros, amoladores de facas, soldadores, mendigos - em suma, toda essa massa indefinida e desintegrada atirada de ceca em meca." (MARX, Karl - Obras escolhidas. São Paulo: Alfa Ômega, s/d., apud: HOHLFELDT, Antônio, 1986, p. 09)

\section{REFERÊNCIAS}

ANDRADE, M. Carta à Ilka Brunhilde. Data 10 de fevereiro de 1997. In: Acervo de João Antônio Assis. São Paulo: Unesp.

ANTÔNIO, J. Abraçado ao meu rancor. Rio de Janeiro: Guanabara, 1986.

. Malagueta, Perus e Bacanaço. Rio de Janeiro: Civilização Brasileira, 1976.

. Patuléia: gentes da rua. São Paulo: Ática, 2004.

. Leão de chácara. São Paulo: Cosacnaify, 2002.

. Carta à Ilka Brunhilde. Data 01 de setembro de 1959. In: Acervo de João Antônio Assis. São Paulo: Unesp.

. Carta à Ilka Brunhilde. Data 23 de set., de 1959. In: Acervo de João Antônio Assis. São Paulo: Unesp. 
. Carta à Ilka Brunhilde. Data 07 de mar., de 1960. In: Acervo de João Antônio. Assis-SP-UNESP.

AZEVEDO FILHO, C. A. F. "Vagabundos \& Malandros: máximo Górki e João Antônio". In: Papeis de escritor: leituras sobre João Antônio. (Orgs.) Oliveira, Ana Maria Domingues, Ornellas, Clara Ávila \& Silva, Telma Maciel. Assis: FCL-Assis-UNESP, 2008.

BAKHTIN, M. (Voloshinov). Marxismo e Filosofia da Linguagem: Problemas Fundamentais do Método Sociológico na Ciência da Linguagem. São Paulo: Hucitec, 1981.

. A Estética da Criação Verbal. São Paulo: Martins Fontes, 2000.

BRUNHILDE, I. L. Cartas a João Antônio. Data 2 ou 4 de set., 1959/60? In: Acervo de João Antônio. Assis-SP-UNESP.

. Data 14 de agosto de 1960. In: Acervo de João Antônio Assis. São Paulo: Unesp.

. Data 8 de agosto de 1968. In: Acervo de João Antônio Assis. São Paulo: Unesp.

. Data 16 de março de 1969. In: Acervo de João Antônio Assis. São Paulo: Unesp.

. Data 12 de outubro de 1975. In: Acervo de João Antônio Assis. São Paulo: Unesp.

. Data 12 de dezembro de 1982. In: Acervo de João Antônio Assis. São Paulo: Unesp.

. Data 23 abril de 1983. In: Acervo de João Antônio Assis. São Paulo: Unesp.

DURIGAN, J.A. João Antonio e a ciranda da malandragem. In: Schwarz, Roberto (Org.). Os pobres na literatura brasileira. São Paulo: Brasiliense, 1983.

MACÊDO, T. Prefácio: Malandros e merdunchos. In: ANTÔNIO, João Antônio. Leão de Chácara. São Paulo: Cosac Naify, 2002. 184 p.

RIBEIRO NETO, J.S. Literatura comentada: João Antônio/seleção de textos, notas, estudos biográfico, histórico e crítico e exercícios. São Paulo: Abril, 1981.

RODRIGUES, R.H. Os Gêneros do Discurso na Perspectiva Dialógica da Linguagem: A Abordagem de Bakhtin. In: MEURER, J. L; BONINI, A. \& MOTTA-ROTH, D. Gêneros: Teorias, Métodos e Debates. São Paulo: Parábola, 2005. p. 152-183. 